\title{
Identification of Trypanosoma cruzi Discrete Typing Units (DTUs) through the implementation of a High-Resolution Melting (HRM) genotyping assay
}

\author{
Sonia L Higuera ${ }^{\dagger}$, Felipe Guhl ${ }^{*}$ and Juan David Ramírez ${ }^{\dagger}$
}

\begin{abstract}
Background: Chagas disease, caused by Trypanosoma cruzi, is a geographically widespread anthropozoonosis that is considered a major public health problem in Latin America. Because this parasite presents high genetic variability, a nomenclature has been adopted to classify the parasite into six discrete typing units (DTUs): Tcl, Tcll, Tclll, TcIV, $T c V$, and TcVl, which present different eco-epidemiological, clinical, and geographic associations. Currently, the available genotyping methods present a series of drawbacks that implies the need for developing new methods for characterizing T. cruzi DTU's. The aim of this work was to genotype reference populations from T. cruzi by means of a High-Resolution Melting (HRM) genotyping assay.

To genotype the DTUs of 38 strains and 14 reference clones of T. cruzi from diverse sources, real-time PCR (qPCR) was coupled to high-resolution melting (HRM) based on the amplification of two molecular markers - the divergent domain of the 24 sa rRNA gene and the intergenic region of the mini-exon gene.

Findings: Amplification of the mini-exon gene allowed the genotyping of three distinct groups: Tcl, Tcll- TcIV- TcV, and TCIII-TCVI, while amplification of the 24sa gene generated non-overlapping melting temperature ranges for each DTU that were used to identify the groups in the six existing DTUs of Trypanosoma cruzi.
\end{abstract}

Conclusions: The proposed genotyping assay allowed discrimination of the six genetic groups by obtaining specific melting curves for each DTU. The application of this technique is proposed because of its specificity, sensitivity, high performance, and low cost compared with other previously described characterization methods.

Keywords: Chagas disease, Trypanosoma cruzi, DTU, high-resolution melting, Genotyping

\section{Findings}

Chagas disease is an anthropozoonosis caused by the parasite Trypanosoma cruzi and affects an estimated 10 million people, posing a serious public health problem [1]. Trypanosoma cruzi has a high genetic variability with evidence of six Discrete Typing Units (DTU's): T. cruzi I (TcI), T. cruzi II (TcII), T. cruzi III (TcIII), T. cruzi IV (TcIV), T. cruzi $\mathrm{V}(\mathrm{TcV})$, and T. cruzi VI (TcVI), each of which presents characteristics based on the geographic distribution, eco-epidemiological associations, and clinical manifestations of the disease [2]. Currently, several methods have been reported for characterizing and genotyping Trypanosoma cruzi populations, including

\footnotetext{
* Correspondence: fguhl@uniandes.edu.co

${ }^{\dagger}$ Equal contributors

Centro de Investigaciones en Microbiología y Parasitología Tropical, CIMPAT, Universidad de Los Andes, Cra $1^{a}$ No. 18a-10, Bogotá, Colombia
}

the PCR amplification of the SL-IR (spliced-leader intergenic region of the mini-exon gene), $24 \mathrm{~s} \alpha$, and $18 \mathrm{~s}$ rDNA gene regions. The comparison criterion for this technique is based on the size differences in the resulting amplicons [3,4]. However, the characterization obtained using this technique is limited by the absence of amplification products or the need for multiple amplification procedures [2,5]. Another proposed methodology is based on genetic polymorphism analysis using multilocus PCR-RFLP; however, this technique requires the development of combinations and multiple assays, increasing its complexity and limiting its use [6,7]. In 2009, Llewellyn and colleagues implemented an approach based on the Multilocus Microsatellite Typing (MLMT) of a panel of 48 polymorphic microsatellite markers. This technique is a quick and feasible alternative but requires the inclusion of sequencing procedures that lead to increased costs [8]. A 
Table 1 Biological and geographical origin of the 36 reference strains and 18 reference clones of Trypanosoma cruzi previously genotyped by MLEE, MLST and MLMT employed in the HRM analyses

\begin{tabular}{|c|c|c|c|}
\hline DTU & Strain/clone & Geographical origin & Biological origin \\
\hline \multirow{14}{*}{$\mathrm{Tcl}$} & X10610 & Guárico, Venezuela & Homo sapiens \\
\hline & 92101601 & Georgia, USA & Didelphis marsupialis \\
\hline & Cutia $\mathrm{Cl} 1^{*}$ & Espiritu Santo, Brazil & Dasyprocta aguti \\
\hline & $\mathrm{DM} 28$ & Carabobo, Venezuela & Didelphis marsupialis \\
\hline & $\mathrm{JrCl} 4^{*}$ & Anzoátegui, Venezuela & Homo sapiens \\
\hline & $\times 101$ & Pará, Brazil & Homo sapiens \\
\hline & Saxp18 & Maje, Perú & Homo sapiens \\
\hline & Chilec22* & Flor de Valle, Chile & Triatoma spinolai \\
\hline & 10r 26 & Santa Cruz, Bolivia & Aotus sp. \\
\hline & c8 & La Paz, Bolivia & Triatoma infestans \\
\hline & ERA & Anzoátegui, Venezuela & Homo sapiens \\
\hline & SP104Cl1* & Región IV, Chile & Mepraia spinolai \\
\hline & P209c193* & Sucre, Bolivia & Homo sapiens \\
\hline & OPS21 di11* & Cojedes, Venezuela & Homo sapiens \\
\hline \multirow{9}{*}{ Tcll } & MASCl1* & Minas Gerais, Brazil & Homo sapiens \\
\hline & IWcl4* & Cuncumen, Chile & Homo sapiens \\
\hline & Pot $7 b$ & San Martin, Paraguay & Triatoma infestans \\
\hline & CBB & Tulahuen, Chile & Homo sapiens \\
\hline & Pot 7a Cl* & San Martin, Paraguay & Triatoma infestans \\
\hline & Chaco 23 & Chaco, Paraguay & Triatoma infestans \\
\hline & $\mathrm{EBC} 121^{*}$ & Boyacá, Colombia & Homo sapiens \\
\hline & Tu18 & Tupiza, Bolivia & Triatoma infestans \\
\hline & ESM & Sao Felipe, Brazil & Homo sapiens \\
\hline \multirow{6}{*}{ Tclll } & $85 / 847$ & Alto Beni, Bolivia & Dasypus novemcinctus \\
\hline & M6421 & Belem, Brazil & Homo sapiens \\
\hline & SLDN1 & Casanare, Colombia & Dasypus novemcintus \\
\hline & Ua2 & Sucre, Bolivia & Dasypus novemcintus \\
\hline & SABPI9 & Vitor, Perú & Triatoma infestans \\
\hline & M5631 Cl5* & Marajo, Brazil & Dasypus novemcinctus \\
\hline \multirow{5}{*}{ TcIV } & Stc10r & Georgia, USA & Procyon lotor \\
\hline & 92122 & Georgia, USA & Procyon lotor \\
\hline & CANIII & Belem, Brazil & Homo sapiens \\
\hline & TV & Boyacá, Colombia & Triatoma venosa \\
\hline & DOG THEIS & Oklahoma, USA & Canis familiaris \\
\hline \multirow{8}{*}{ TcV } & 92.80 & Santa Cruz, Bolivia & Homo sapiens \\
\hline & Chaco 9 & Chaco, Paraguay & Triatoma infestans \\
\hline & Para6 & Chaco, Paraguay & Triatoma infestans \\
\hline & PPAH179 CL5* & Chaco, Argentina & Homo sapiens \\
\hline & Chaco 2 CB & Chaco, Paraguay & Triatoma infestans \\
\hline & AACF2 & Casanare, Colombia & Canis familiaris \\
\hline & Para4 & Paraguari, Paraguay & Triatoma infestans \\
\hline & sc43 & Santa Cruz, Bolívia & Triatoma infestans \\
\hline
\end{tabular}

Table 1 Biological and geographical origin of the 36 reference strains and 18 reference clones of Trypanosoma cruzi previously genotyped by MLEE, MLST and MLMT employed in the HRM analyses (Continued)

\begin{tabular}{lll}
\hline Vinch101 & Limarí, Chile & Triatoma infestans \\
MN Cl2* & Region IV, Chile & Homo sapiens \\
BUG2148Cl** & Rio Grande do Sul, Brazil & Triatoma infestans \\
SC43Cl1* & Santa Cruz, Bolivia & Triatoma infestans \\
SO3Cl5* & Potosi, Bolivia & Triatoma infestans \\
LhVa & Chaco, Argentina & Triatoma infestans \\
VfrA & Francia, Chile & Triatoma infestans \\
Tula Cl2* & Tulahuen, Chile & Homo sapiens \\
Rp540 & Casanare, Colombia & Rhodnius prolixus \\
P251 & Cochabamba, Bolivia & Homo sapiens \\
CLBRENER & Rio Grande do Sul, Brazil & Triatoma infestans \\
P63Cl1* & Makthlawaiya, Paraguay & Triatoma infestans \\
\hline
\end{tabular}

*Biological Clones.

similar initiative was proposed to develop a Multilocus Sequence Typing (MLST) scheme based on the analysis of a panel of four molecular targets: Met-III, RB19, TcGPXII, and DHFR-TS; however, the development of this process requires both bioinformatic analysis and sequencing steps [9]. Recently, the analysis of the polymorphisms of the $24 \mathrm{~s} \alpha$ rDNA gene, the subunit II of the cytochrome oxidase, and four microsatellite loci has been shown to be an alternative method [10]. This technique is highly efficient but requires multiple amplification steps that can lead to an increased risk of contamination.

Thus, a low-cost genotyping technique with reliable and robust results for the identification of the six genetic groups in a single assay is needed to facilitate the characterization of the circulating strains in a specific geographic area. A technique such as High-Resolution Melting (HRM) offers a viable alternative for genotyping T. cruzi given its robustness, speed, cost, and the elimination of sequencing or hybridization procedures [11]. This molecular analysis has recently been used to genotype different populations of parasitic microorganisms [12-15]. The aim of this study was to genotype 36 reference strains and 18 reference clones of Trypanosoma cruzi previously genotyped by different molecular markers from different biological and geographical origins via HRM.

We employed 36 strains and 18 reference clones of Trypanosoma cruzi previously characterized via MLST, MLEE, MLMT, and RFLP-PCR (Table 1). Additionally, in order to test specificity we included DNA from reference strains of $T$. rangeli and Leishmania panamensis. A real-time PCR assay coupled with HRM analysis was developed to target SL-IR and the 24s $\alpha$ rRNA gene using a 7500 Fast Real-Time PCR System (Applied Biosystems, Inc., CA, USA). These genes were selected because they 


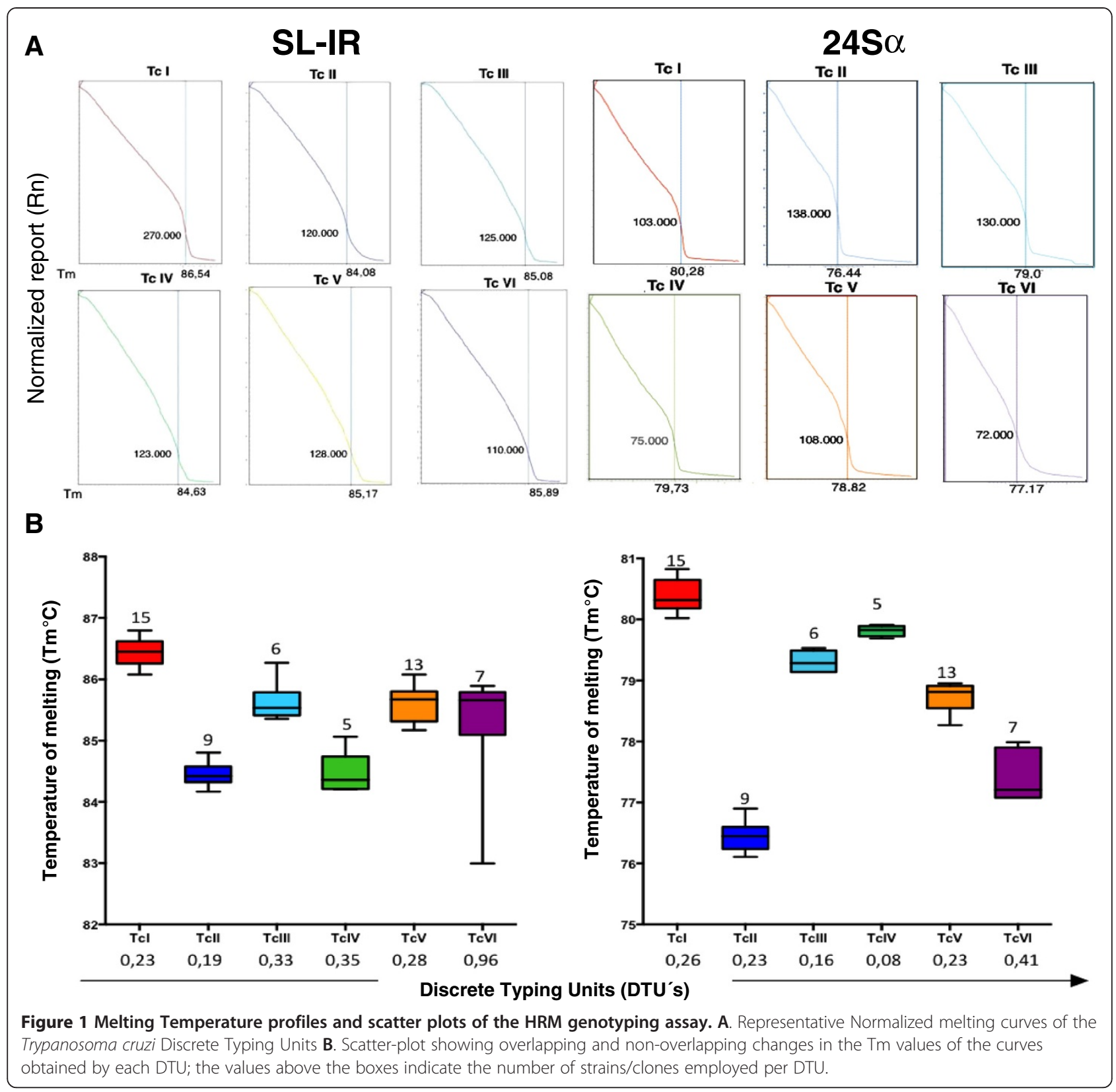

had previously been used as molecular markers for the PCR genotyping of T. cruzi $[4,16]$. The amplification reactions were carried out in a total volume of $21 \mu \mathrm{L}$. The reaction mixture consisted of $1 \times$ MeltDoctor ${ }^{\text {TM }}$ HRM Master Mix (Applied Biosystems, Inc., CA, USA); a $5 \mu \mathrm{M}$ solution of each of the primers TCC $\left(5^{\prime} \mathrm{CCC}\right.$ CCC TCC CAG GCC ACA CTG 3) and TC2 (5'CCT GCA GGC ACA cGT GTG TGT G 3) for the amplification of SL-IR and 24s $\alpha$, D71 (5'AAG GTG CGT CGA CAG TGT GG 3) and D72 (5'TTT TCA GAA TGG CCG AAC AGT 3); $6.6 \mu \mathrm{L}$ of water; and $20 \mathrm{ng} / \mu \mathrm{L}$ DNA template. The cycle conditions for the qPCR were as follows: $95^{\circ} \mathrm{C}$ for 10 minutes ( 1 cycle), followed by amplification for 40 cycles at $95^{\circ} \mathrm{C}$ for 15 seconds (denaturation) and $60^{\circ} \mathrm{C}$ for 1 minute. The amplicon dissociation was immediately initiated by a melting step. The thermal profile consisted of denaturation at $95^{\circ} \mathrm{C}$ for 10 seconds, $60^{\circ} \mathrm{C}$ for 1 minute (annealing), $95^{\circ} \mathrm{C}$ for 30 seconds (high-resolution melting), and a final annealing stage at $60^{\circ} \mathrm{C}$ for 15 seconds. The melting curve analysis was carried out by supplying raw fluorescence (F) vs. temperature $(\mathrm{T})$ values or already transformed $-\mathrm{dF} / \mathrm{dT}$ values. The raw value,differentiation was performed and the first derivative curve is displayed with the melting peaks. Peaks and Tm values were automatically identified, peak areas calculated and peaks flagged as 'negative' if the peak area is below the user-defined threshold value. During 
this process, the PCR amplicons were denatured prior to developing the melting curves, and the changes in fluorescence with respect to the changes in temperature $(\mathrm{dF} / \mathrm{dT})$ were recorded by the instrument with a ramp of $0.5^{\circ} \mathrm{C} / \mathrm{seg}$. Each DNA sample was analyzed in duplicate. Finally, the normalized and derivative melting curve profiles were obtained. The analysis was performed using a blind methodology to reduce the possibility of bias. To evaluate the reproducibility of the assay, the genotyping technique was performed on five independent days under the same conditions. The specificity was assessed by evaluating the concordance between the pre-established genotypes of the DNA samples used and the genotypes characterized by HRM. The consistency of the method was determined by correlating the previously quantified reproducibility and specificity [17]. Finally, a randomization and subsequent non-parametric Kruskal Wallis test $(\mathrm{p}<0.05)$ were conducted to detect any significant differences between the melting temperature data for each DTU. The analyses were performed using the $R$ platform and GraphPad software package.

A specific melting temperature was obtained for each of the reference strains and clones included in this study, both for amplifying SL-IR and for the 24s $\alpha$. The plots were created for the melting temperature distribution of each DTU (Figure 1). The $24 \mathrm{~s} \alpha$ gene exhibited higher discriminatory power than the SL-IR gene, producing non-overlapping ranges of the melting temperature for each DTU. The normalized fluorescence curve and the derivative melting curve yielded a different and easily distinguishable profile for each DTU. The representative profiles were collected for the derivative, the normalized melting curves for the SL-IR gene and the 24s $\alpha$ amplicons (Figure 1). Finally, an algorithm was constructed (Figure 2) which allowed the discrimination of the DTU's after the amplification of the SL-IR gene and the subsequent amplification of the $24 s \alpha$ gene. To validate the method, three parameters were determined based on the methodology of Moncayo and Luquetti (1990) [17]; the reproducibility was determined for both the SL-IR gene amplification and the $24 s \alpha$ rRNA and yielded a value of $100 \%$ for both tests. The specificity and consistency values were obtained only for the amplification of the 24s $\alpha$ rRNA, which was the only marker capable of generating non-overlapping melting temperature ranges that was specific for the six DTU's and the DNAs from T. rangeli and L. panamensis.

The use of the HRM methodology allowed the adequate and congruent discrimination of the T. cruzi genotypes for the strains and reference clones used. Many problems, such as the need for sequencing, the degree of complexity, the design of multiple pairs of primers, and genotyping by the absence of a band, among others, have been reported with the existing genotyping methods. Thus, new alternatives are needed to simplify the process and minimize the difficulties. For example, methods based on the absence of an amplification product are considered problematic because no actual evidence is generated that may relate to the presence of a specific DTU [2]. To obtain a correct identification, other genotyping methods for which high efficiency, sensitivity, and robustness have been reported require multiple amplifications of a single sample using different markers or coupled with RAPD's and RFLP analysis, which can significantly increase the economic cost and lead to sample contamination [18]. The HRM technique does not present any of the aforementioned difficulties and, given the as-obtained results, could be considered a potential alternative strategy for genotyping T. cruzi.

The markers were selected based on two criteria: the fact that both the SL-IR gene and the 24s $\alpha$ rRNA have previously been used to characterize T. cruzi and because they exhibit a high number of copies within the parasite genome, which increases the probability of detection $[6,19,20]$. The results of this study indicated that the SL-IR gene did not allow the absolute discrimination of the

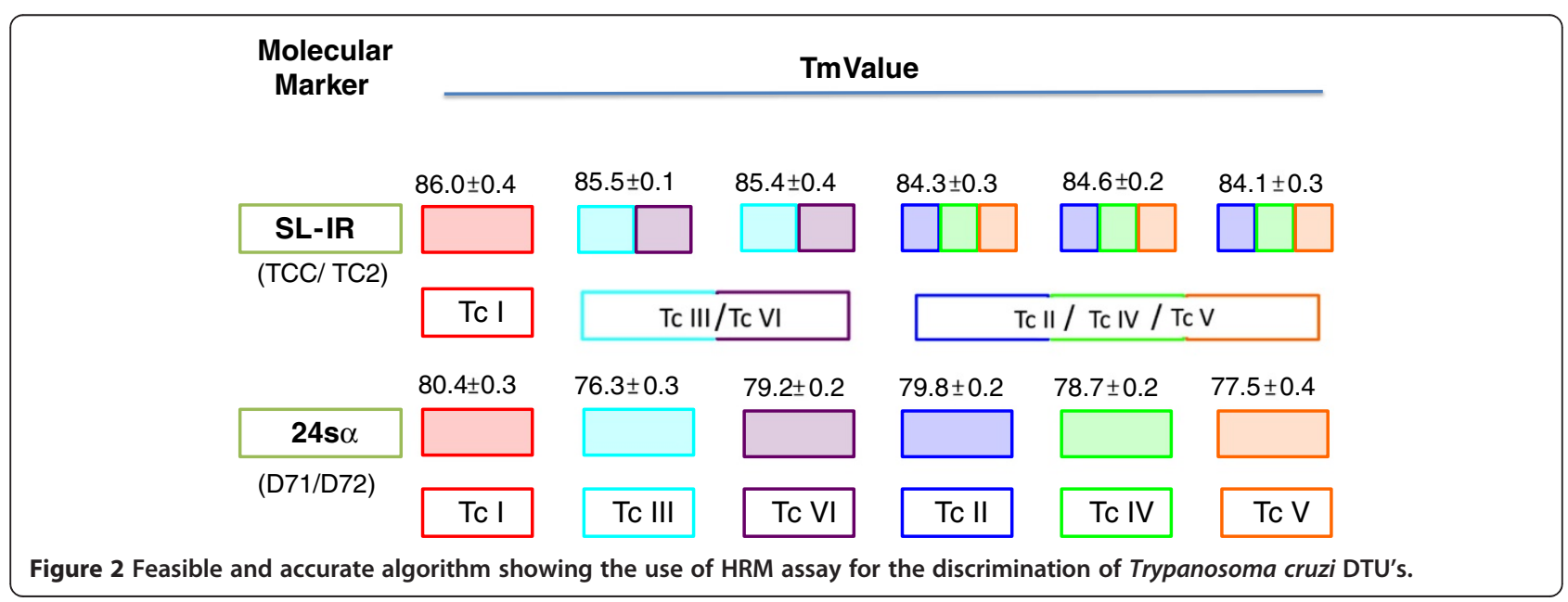


six DTUs in a single assay, a fact that may be due to the recently confirmed variation in the copy number of the gene and the chromosomal rearrangement at the level of the different strains [21]. To examine the reproducibility of the method, the assays were conducted in duplicate, and the tests were repeated over several days, maintaining the same test conditions, reagent quantities, and DNA concentrations. The technique generated a reproducibility value of $100 \%$ for both molecular markers. This result is of great significance because genotyping techniques must be reproducible and robust to avoid producing conflicting results and to accurately establish the genotype of each sample analyzed [22].

\section{Conclusion}

The use of a real-time PCR assay coupled with HRM analysis is proposed for genotyping the DTU's of the T. cruzi population for the development of research projects that require genotyping of the circulating strains because it provides an easy, quick, and low (1.5 USD per assay compared to 2.5 USD for genotyping) alternative compared to the existing methods. Among the advantages over other currently used methods are its speed and simplicity (given that this method does not require gel electrophoresis), the reduction of the processing time, and the specificity and sensitivity of the method [14]. Therefore, HRM coupled to qPCR provides a cost-effective alternative for the future genotyping and identification of the six DTU's of T. cruzi which fulfills one of the main research targets in Chagas disease.

\section{Abbreviations \\ DTU: Discrete Typing Unit; Tcl: Trypanosoma cruzi l; Tcll: Trypanosoma cruzi II; Tclll: Trypanosoma cruzi III; TcIV: Trypanosoma cruzi IV; TCV: Trypanosoma cruzi V; TcVl: Trypanosoma cruzi VI; HRM: High-Resolution Melting; SL-IR: Spliced Leader Intergenic Region.}

\section{Competing interests}

The authors declare that they have no competing interest.

\section{Authors' contributions}

JDR designed the experiments. SLH and JDR standardized the HRM assay and developed the experiments to calculate the parameters of reproducibility and specificity. SLH, JDR and FG wrote the manuscript. All authors read and approved the final version of the manuscript.

\section{Acknowledgements}

We thank IRD and LSHTM for providing the DNA of the reference strains and clones in the framework of the Chagas EpiNet project. Financial support was provided by the Project Chagas EpiNet from The European Union Seventh Framework Programme, contract no.223034.

Received: 5 March 2013 Accepted: 11 April 2013

Published: 20 April 2013

\section{References}

1. Rassi A Jr, Rassi A, de Rezende M: American Trypanosomiasis Chagas Disease. Infect Dis Clin North Am 2012, 262:275-291.

2. Zingales B, Miles MA, Campbell DA, Tibayrenc M, Macedo AM, Teixeira MM, Schijman AG, Llewellyn MS, Lages-Silva E, Machado CR, Andrade SG, Sturm NR: The revised Trypanosoma cruzi subspecific nomenclature: Rationale, epidemiological relevance and research applications. Infect Genet Evol 2012, 122:240-253.

3. Brisse S, Verhoef J, Tibayrenc M: Characterization of large and small subunit rRNA and mini-exon genes further supports the distinction of six Trypanosoma cruzi lineages. Int J Parasitol 2001, 311:1218-1226.

4. Souto RP, Fernandes O, Macedo AM, Campbell DA, Zingales B: DNA markers define two major phylogenetic lineages of Trypanosoma cruzi. Mol Biochem Parasitol 1996, 83:141-152.

5. Burgos JM, Diez M, Vigliano C, Bisio M, Risso M, Duffy T, Cura C, Brusses B, Favaloro L, Leguizamon MS, Lucero RH, Laguens R, Levin MJ, Favaloro R, Schijman AG: Molecular Identification of Trypanosoma cruzi Discrete Typing Units in End-Stage Chronic Chagas Heart Disease and Reactivation after Heart Transplantation. Clin Inf Dis 2010, 515:485-495.

6. Rozas M, Doncker S, Adaui V, Coronado X, Barnabé C, Tibayrenc M, Solari A, Dujardin JC: Multilocus polymerase chain reaction restriction fragmentlength polymorphism genotyping of Trypanosoma cruzi (Chagas disease): taxonomic and clinical applications. J Infect Dis 2007, 195:1381-8.

7. Lewis MD, Ma J, Yeo M, Carrasco HJ, Llewellyn MS, Miles MA: Genotyping of Trypanosoma cruzi: systematic selection of assays allowing rapid and accurate discrimination of all known lineages. Am JTrop Med Hyg 2009, 81:1041-1049.

8. Llewellyn MS, Miles MA, Carrasco HJ, Lewis MD, Yeo M, Vargas J, Torrico F, Diosque P, Valente SA, Gaunt MW: Genome-scale multilocus microsatellite typing of Trypanosoma cruzi discrete typing unit I reveals phylogeographic structure and specific genotypes linked to human infection. PLoS Pathog 2009, 5:e1000410.

9. Yeo M, Mauricio IL, Messenger LA, Lewis MD, Llewellyn MS, Acosta N, Bhattachaeyya T, Diosque P, Carrasco HJ, Miles MA: Multilocus Sequence Typing MLST for Lineage Assignment and High Resolution Diversity Studies in Trypanosoma cruzi. PLoS Negl Trop Dis 2011, 56:e1049.

10. Valadares HMS, Pimenta JR, Segatto M, Veloso VM, Gomes ML, Chiari E, Gollob KJ, Bahia M, de Lana M, Franco GR, Machado CR, Pena SD, Macedo AM: Unequivocal Identification of Subpopulations in Putative Multiclonal Trypanosoma cruzi Strains by FACs Single Cell Sorting and Genotyping. PLOS Negl Trop Dis 2012, 67:e1722. doi:10.1371/journal.pntd.0001722.

11. Schütz $E$, von Ahsen N: Influencing factors of dsDNA dye high.resolution melting curves and improved genotype call based on thermodynamic considerations. Anal Biochem 2009, 3851:143-152.

12. Zhang P, Liu Y, Alsarakibi M, Li J, Liu T, Li Y, Li G: Application of HRM assays with EvaGreen dye for genotyping Giardia duodenalis zoonotic assemblages. Parasitol Res 2012, 111:2157-2163.

13. Al-Mohammed $\mathrm{H}$ : Genotypes of Giardia intestinalis clinical isolates of gastrointestinal symptomatic and asymptomatic Saudi children. Parasitol Res 2011, 108:1375-1381.

14. Ngui R, Lim YA, Chua KH: Rapid Detection and Identification of Human Hookworm Infections through High Resolution Melting HRM Analysis. PLoS One 2012, 77:e41996.

15. Costa JM, Cabaret O, Moukoury S, Bretagne S: Genotyping of the protozoan pathogen Toxoplasma gondii using high-resolution melting analysis of the repeated B1 gene. J Microbiol Met 2011, 863:357-363.

16. Ramírez JD, Guhl F, Rendón LM, Rosas F, Marin-Neto JA, Morillo CA: Chagas Cardiomyopathy Manifestations and Trypanosoma cruzi Genotypes Circulating in Chronic Chagasic Patients. PLoS Neg Trop Dis 2010, 41:e899.

17. Moncayo A, Luquetti AO: Multicentre double blind study for evaluation of Trypanosoma cruzi defined antigens as diagnostic reagents. Mem Inst Oswaldo Cruz 1990, 85:489-495.

18. Peña VH, Fernández GJ, Gómez-Palacio AM, Mejía-Jaramillo AM, Cantillo O, Triana-Chávez O: High-Resolution Melting HRM of the Cytochrome B Gene: A Powerful Approach to Identify Blood-Meal Sources in Chagas Disease Vectors. PLoS Neg Trop Dis 2012, 62:e1530.

19. Cardinal MV, Lauricella MA, Ceballos LA, Lanati L, Marcet PL, Levin MJ, Kitron U, Gürtler RE, Schijman AG: Molecular epidemiology of domestic and sylvatic Trypanosoma cruzi infection in rural northwestern Argentina. Int J Parasitol 2008, 381:1533-1543.

20. Messenger LA, Llewellyn MS, Bhattacharyya T, Franzén O, Lewis MD, Ramírez JD, Carrasco HJ, Andersson B, Miles MA: Multiple Mitochondrial Introgression Events and Heteroplasmy in Trypanosoma cruzi Revealed by Maxicircle MLST and Next Generation Sequencing. PLOS Neg Trop Dis 2012, 64:e1584.

21. Minning TA, Weatherly DB, Flibotte $S$, Tarleton RL: Widespread, focal copy number variations CNV and whole chromosome aneuploidies in 
Trypanosoma cruzi strains revealed by array comparative genomic hybridization. BMC Genom 2011, 121:139-146.

22. Hong H, Xu L, Liu J, Jones WD, Su Z, Ning B, Perkins R, Ge W, Miclaus K, Zhang L, Park K, Green B, Han T, Fang H, Lambert CG, Vega SC, Lin SM, Jafari N, Czika W, Wolfinger RD, Goodsaid F, Tong W, Shi L: Technical Reproducibility of Genotyping SNP Arrays Used in Genome-Wide Association Studies. PLoS One 2012, 79:e44483.

doi:10.1186/1756-3305-6-112

Cite this article as: Higuera et al.: Identification of Trypanosoma cruzi

Discrete Typing Units (DTUs) through the implementation of a High-

Resolution Melting (HRM) genotyping assay. Parasites \& Vectors 2013 6:112.

\section{Submit your next manuscript to BioMed Central and take full advantage of:}

- Convenient online submission

- Thorough peer review

- No space constraints or color figure charges

- Immediate publication on acceptance

- Inclusion in PubMed, CAS, Scopus and Google Scholar

- Research which is freely available for redistribution 